\title{
Corrigendum: Effects of Hsp90 Inhibitor Ganetespib on Inhibition of Azole-Resistant Candida albicans
}

\section{OPEN ACCESS \\ Edited and reviewed by: Ying-Chun Xu, Peking Union Medical College Hospital (CAMS), China \\ *Correspondence: Xi Chen \\ xchen@nwu.edu.cn Na Liu \\ liuna@smmu.edu.cn}

Specialty section: This article was submitted to Antimicrobials, Resistance and Chemotherapy,

a section of the journal Frontiers in Microbiology

Received: 09 September 2021 Accepted: 30 September 2021 Published: 19 October 2021

Citation:

Yuan R, Tu J, Sheng C, Chen X and Liu N (2021) Corrigendum: Effects of Hsp90 Inhibitor Ganetespib on Inhibition of Azole-Resistant Candida albicans. Front. Microbiol. 12:773140.

doi: 10.3389/fmicb.2021.773140

\author{
Rui Yuan ${ }^{1}$, Jie $\mathrm{Tu}^{2}$, Chunquan Sheng ${ }^{2}, \mathrm{Xi} \mathrm{Chen}^{1 *}$ and Na Liu ${ }^{2 *}$ \\ ${ }^{1}$ Key Laboratory of Synthetic and Natural Functional Molecule of the Ministry of Education, College of Chemistry and \\ Materials Science, Northwest University, Xi'an, China, ${ }^{2}$ School of Pharmacy, Second Military Medical University, Shanghai, \\ China
}

Keywords: Hsp90, Candida albicans, antifungal activity, ganetespib, drug resistance

\section{A Corrigendum on}

Effects of Hsp90 Inhibitor Ganetespib on Inhibition of Azole-Resistant Candida albicans by Yuan, R., Tu, J., Sheng, C., Chen, X., and Liu, N. (2021). Front. Microbiol. 12:680382. doi: $10.3389 /$ fmicb.2021.680382

In the original article, there was a mistake in Figure 3 as published. In Figure 3B, the wrong image was used for the filamentation microscopic figure of C. albicans 0304103 treated with Ganetespib $(32 \mu \mathrm{g} / \mathrm{mL})$. The corrected Figure 3 appears below.

The authors apologize for this error and state that this does not change the scientific conclusions of the article in any way. The original article has been updated.

Publisher's Note: All claims expressed in this article are solely those of the authors and do not necessarily represent those of their affiliated organizations, or those of the publisher, the editors and the reviewers. Any product that may be evaluated in this article, or claim that may be made by its manufacturer, is not guaranteed or endorsed by the publisher.

Copyright () 2021 Yuan, Tu, Sheng, Chen and Liu. This is an open-access article distributed under the terms of the Creative Commons Attribution License (CC BY). The use, distribution or reproduction in other forums is permitted, provided the original author(s) and the copyright owner(s) are credited and that the original publication in this journal is cited, in accordance with accepted academic practice. No use, distribution or reproduction is permitted which does not comply with these terms. 
A
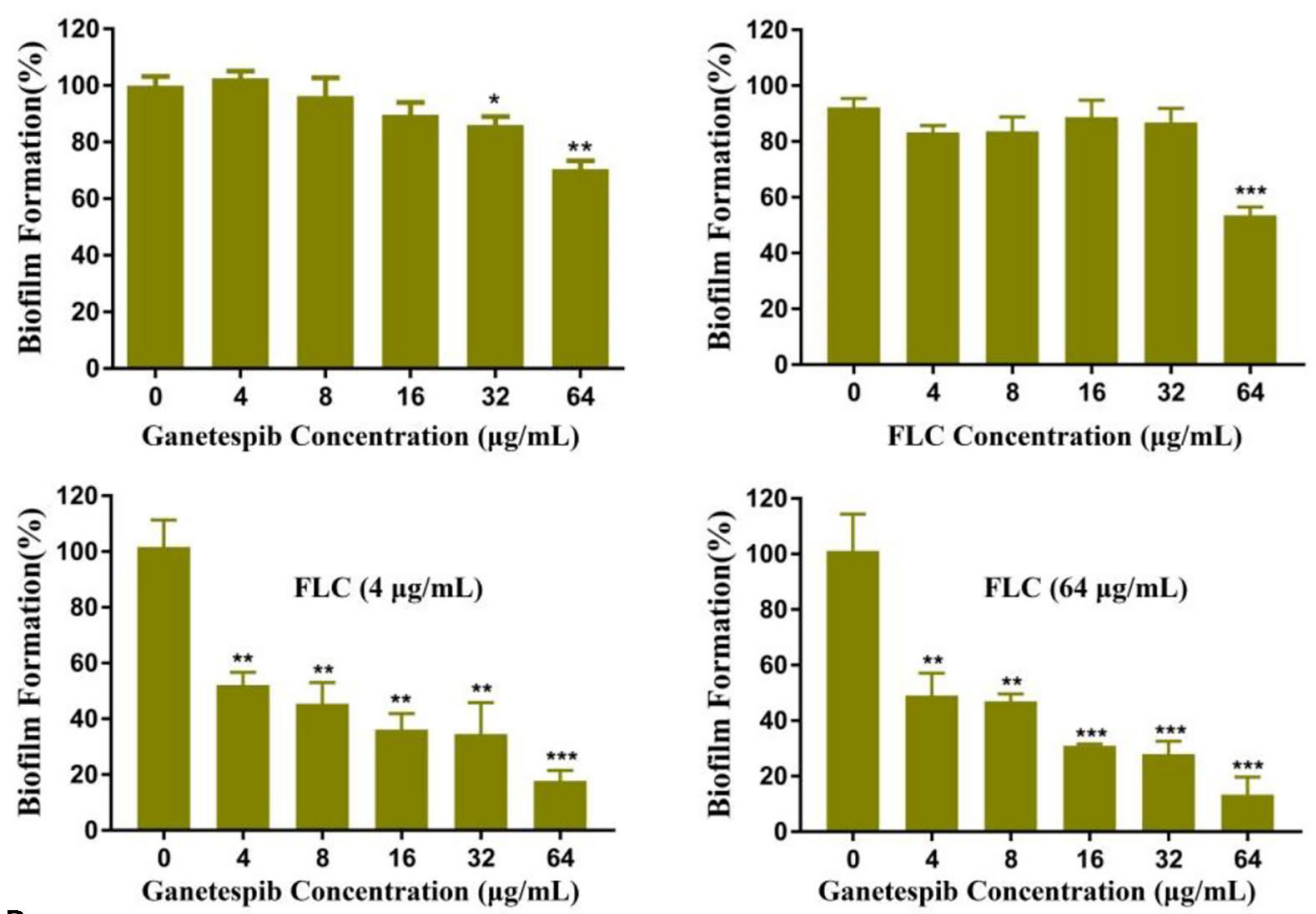

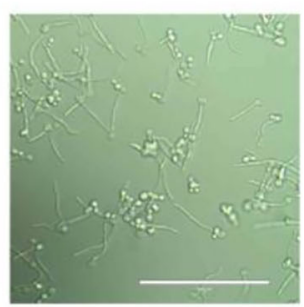

Blank

C

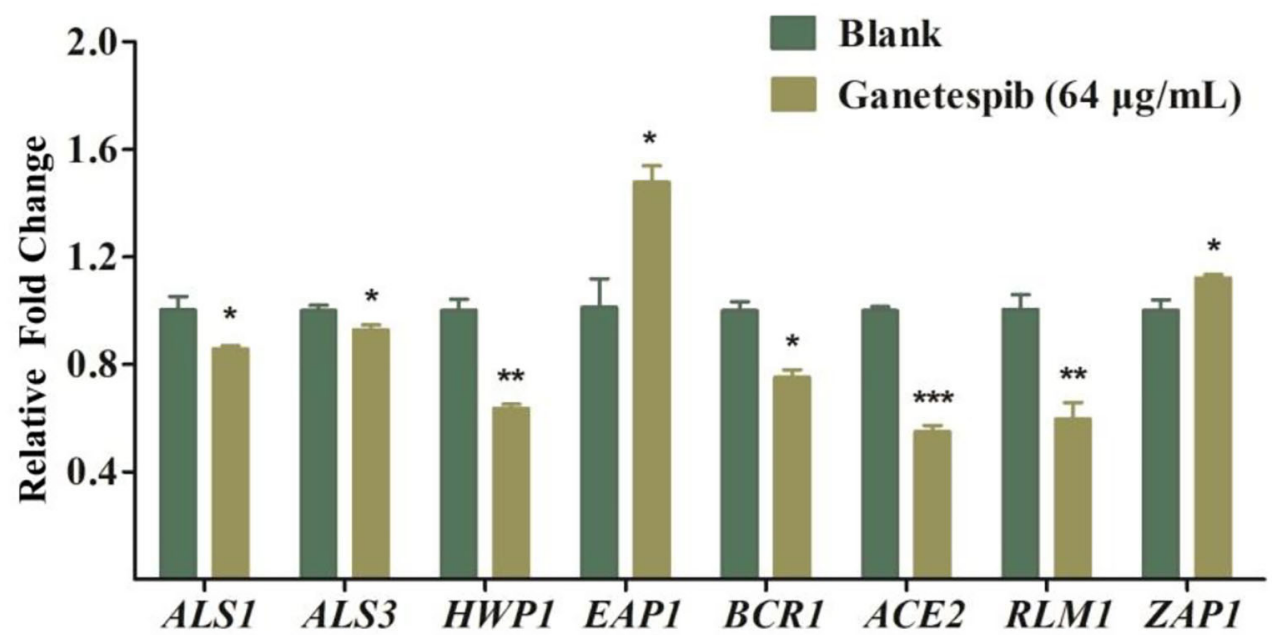

FIGURE 3 | (A) Effect of ganetespib, FLC, or both on the C. albicans 0304103 biofilm formation. (B) Filamentation microscopic observation of C. albicans 0304103 treated with FLC (F), ganetespib (G), or their combination. (C) Expression levels of biofilm formation-related and filamentation genes $\left({ }^{*} P<0.05,{ }^{* \star} P<0.01,{ }^{\star \star \star} P<\right.$ 0.001 , determined by Student's $t$-test). 